\title{
Zinc Oxide Nanoparticle Reinforced Waste Buffing Dust Based Composite Insole and Its Antimicrobial Activity
}

\author{
Thuhin K. Dey, ${ }^{1}$ Arman Hossain $\mathbb{D}^{1},{ }^{1}$ Mamun Jamal $\mathbb{D}^{2}{ }^{2}$ Rama K. Layek, ${ }^{3}$ \\ and Md. Elias Uddin $\mathbb{D}^{1}$ \\ ${ }^{1}$ Department of Leather Engineering, Faculty of Mechanical Engineering, Khulna University of Engineering \& Technology, \\ Khulna 9203, Bangladesh \\ ${ }^{2}$ Department of Chemistry, Faculty of Civil Engineering, Khulna University of Engineering \& Technology, Khulna 9203, Bangladesh \\ ${ }^{3}$ School of Engineering Science, Department of Separation Science, LUT University, Mukkulankatu 19, FI-15210 Lahti, Finland
}

Correspondence should be addressed to Md. Elias Uddin; eliasuddin@le.kuet.ac.bd

Received 13 September 2021; Accepted 12 January 2022; Published 25 January 2022

Academic Editor: Gyorgy Szekely

Copyright (C) 2022 Thuhin K. Dey et al. This is an open access article distributed under the Creative Commons Attribution License, which permits unrestricted use, distribution, and reproduction in any medium, provided the original work is properly cited.

The objective of this research is to use zinc oxide nanoparticles (ZnONPs) combined with buffing dust to develop footwear insole with antibacterial properties. In addition, performance analysis (mechanical, chemical, and thermal) of fabricated insole is also the integral consideration of this study. With such aim, antimicrobial composite insoles were fabricated via simple solution mixing of ZnONPs and natural rubber latex (NRL) binder along with buffing dusts with optimum ratio. Then, removal of water was considered by mechanical pressing followed by natural drying in sunlight. The chemical bonding and material interactions of composites were investigated using FT-IR and XRD, respectively. TGA analysis confirmed the thermal stability of composites, while SEM and OTR are elucidating the surface morphology and gas barrier properties, respectively. Tensile strength, elongation, flexibility, hardness, and water absorption of prepared composite with optimum NRL content were increased by 39 , $31,30,38$, and $28 \%$, respectively. Finally, $78 \%$ antimicrobial performance was achieved against the suspension of $\left(1.5 \times 10^{6} \mathrm{CFU} / \mathrm{mL}\right)$ bacterial strain Staphylococcus aureus.

\section{Introduction}

Human foot is an important part to propel and carry the whole-body weight. It is incorporated with 140,000 sweat glands, compared to around 60,000 on the dorsal surface. So, it has natural tendency to sweat via thermoregulation during the use of footwear and causes the favorable environment for pathogenic microorganism formation. Initially, sweat is odorless, but bacterial degradation resulting bad smells inside of footwear with favorable humidity and temperature [1-5]. Basically, insole is a synthetic or leatherbased material with foot bottom sandwiched between the shoe outsole and feet. As a result, during walking, insole is more frequently encountered by foot skin rather than shoe upper and outsole. So, the prime concern of insole is to provide foot comfort with moisture transport (sweat) efficiency. Other salient features including mitigation of foot disorders, sweats, bad odor, microorganisms, and ultimate foot balance are also important to ensure [6-8]. Particularly, in case of athletic shoes, breathability of insole with antimicrobial properties is more crucial [3]. So, it is important to eradicate the possibility of bacterial growth in footwear to ensure comfort and hygiene properties simultaneously.

With such motivation, a variety of studies are carried out to impart antimicrobial property in upper leather by using moisture absorbency materials like activated charcoal and silica pack. Moreover, injection of additional heavy metals like selenium, nickel, cobalt, and copper as well as synthetic biocides or fungicides is also experimented to terminate microbial growth. But utilization of these materials simultaneously encounters the health safety with toxicity during direct contact of human foot [9-11]. As a result, the genesis of nanoparticles in terms of antimicrobial agent was imperative to solve this problem. Because nanoparticles are subsuming additional 
features with antimicrobial prospect including high specific surface, fine particles, and easy dispersibility in many medium [12]. For example, Majidnia et al. [12] introduced antibacterial shoe upper leather by using silver nanoparticles, while Idris et al. [13] also developed silver nanoparticles coated surfacemodified leather. On trend, Maestre-López et al. [14], Carvalho et al. [15], and Kaygusuz et al. [16] developed antimicrobial upper leather through the infusion of silver nanocomposites particles and $\mathrm{Ag}-\mathrm{TiO}_{2}$ nanoparticles, respectively. In addition, synthesized nanoparticles from different sources are also promising to consider as an effective antimicrobial agent including cellulose metal nanocomposites, silver grafted biomimetic membrane, and bio-phenols from olive leaf extract [17-19]. Basically, all of these researches are highlighting the potentiality of nanoparticle-based antimicrobial agents in finished leather. Some investigations are also confined into the nanoparticle fabrication rather than their direct field applications. At the same time, studies are only circumscribed within upper leather rather than insole material. But insole is mostly important to consider for tackling microbial growth due to the highest sweat absorption (85-90\%) and still a huge vacuum remained in this investigational point [7]. So, this study is filling such gap with highest novelty though the construction of antimicrobial composite insole.

However, in the field of nanomaterial-based antimicrobial agent, $\mathrm{ZnONPs}$ is emerging as a promising candidate due to their excellent performance against micro-organisms [20, 21]. Because zinc ions $\left(\mathrm{Zn}^{2+}\right)$ can impart excellent antimicrobic performance against different strains of the bacteria and fungi but not harmful for human cells [22-24]. Hence, the antimicrobial shoe insole comprising with $\mathrm{ZnO}$ nanoparticles are considered a promising antimicrobial material for shoe industries. The partial dissolution of zinc oxide $(\mathrm{ZnO})$ releases $\mathrm{Zn}^{2+}$ ions in aqueous suspension contributes antimicrobial activity while two mechanisms including reactive oxygen species formation and direct contact of nanoparticles with microbes cell walls are playing a vital role [25]. In addtion, accumulation of $\mathrm{ZnO}$ nanoparticles in cytoplasm cause cell death due to the disintegration of bacterial cell membrane. [26]. More specifically, cytoplasm is a jelly like liquid and circumscribed by the cell membrane. Such thick solution is regulating the major functions of micro-organisms including cell growth, replication, and metabolism. Thus, accumulation of $\mathrm{ZnO}$ nanoparticles around cytoplasm ultimately inhibits the cellular growth as well as replication and finally causes the bacterial death [23]. In addition, $\mathrm{ZnO}$ nanoparticles can easily penetrate through the uniform layer of peptidoglycan (an integral component of cell wall) and cause the rupturing of it and highly responsible for the bacterial expiration [26].

Nowadays, the circular economy research is getting remarkable attention to valorize the waste material to a valuable product. Hence, utilization of waste buffing to fabricate antimicrobial insole material is very promising to enhance the sustainability of the of shoe insole. Leather processing is more likely to generate higher quantity of solid waste as by products. For example, 1 ton of rawhide causes $850 \mathrm{~kg}$ of solid waste and around 600,000 tons of chromiumtanned solid waste formed globally. Till present, incineration and landfilling are widely used to manage these solid wastes in all over the world. But, at the same time, those processes are also aligned with several problems like groundwater pollution through chromium leaching, drain off the contaminated buffing dust with storm water to aquatic ecosystem and chronic air pollution via thermal incineration of waste buffing dust [27]. In addition, landfilling is also leading to additional disposal costs (U\$ 5.00/m [3]) and responsible for higher manufacturing price. So it is quite obvious to go for precise and controlled recycling management or residues recovery with simultaneous confirmation of business profit and environmental safety [28].

In such phenomena, flexible bio-composite fabrication from discarded buffing dust could be a promising solution of waste minimization. Because, bio-composites are environmental friendly, and direct application of such materials can be considered as a sustainable approach in long run [29]. Thus, considering both tannery waste management as well as the commercial viability, utilization of ZnONPs impregnated waste buffing dust along with natural rubber latex (NRL) based composites could be an effective strategy to attain long-term sustainability.

\section{Materials and Methods}

2.1. Materials. Abandoned waste buffing dust was collected from "SAF Leather Industries Ltd.", Jessore, Bangladesh, and stored in an air-tight bag. Both analytical graded $\mathrm{ZnO}$ nanoparticle dispersion $(<100 \mathrm{~nm}$ particle size $)$ and NRL with 99\% purity were purchased from Sigma Aldrich, Bangladesh.

\subsection{Sample Preparation}

2.2.1. Preparation of Buffing Dust/ZnONP Composites. Buffing dust/ZnONP composite films with various amounts of NRL were prepared by a conventional solution casting technique. For this purpose, steel mold sheet with 12 inch $\times 2$ inch $\times 5$ inch dimension was prepared. Then, $150 \mathrm{~g}$ of buffing dust was crushed in blender to form fine particles and weighted precisely to prepare five different composites. $300 \mathrm{~mL}$ of distilled water was then added to soak buffing dust for the preparation of uniform buffing paste and left overnight for proper wetting. After that, ZnONPs and NRL binder were mixed thoroughly in different ratios (mentioned below) to ensure optimum result. Then, mixer was placed in steel sheet and pressed by masonry trowel to form a uniform surface. The finishing was done carefully and left for 3 days under the sunlight to ensure proper drying and bonding. At next, composite transferred to foil paper and wrapped well for hydraulic ironing press machine. Both sides of the composite were pressed for 10 seconds under $90^{\circ} \mathrm{C}$ and 138 bar. Again, the composite was left for 3 days under direct sunlight for proper drying as well as bonding and then considered as final samples. In this whole process, different ratios were studied to prepare five tasting samples (in gram); buffing dust: water: NRL: ZnONPs for (S1) sample 1: $1: 2: 1.5: 0.1$, (S2) sample 2: $1: 2: 1.7: 0.15$, (S3) sample 3: $1: 2: 1.9: 0.2$, (S4) sample $4: 1: 2: 2.1: 0.25$, (S5) sample 5 : $1: 2: 2.3: 0.3$, respectively. 
2.3. Preparation of Bacterial Suspension. In this study, bacterial strain like Staphylococcus aurous (Genealogy: ATCC 6538, gram-positive) was considered to prepare suspension. The bacteria were cultured in agar media while it was incubated for 24 hours in an incubator with the temperature of $37^{\circ} \mathrm{C}$. Then, bacterial colonies were found in agar plate, and some of them were transferred and dissolved into the salt serum until to have $0.5 \mathrm{McFarland}$ standard turbidity scale $\left(1.5 \times 10^{6} \mathrm{CFU} / \mathrm{ml}\right)$ [12].

2.4. Sample Characterization. Different physical, chemical, morphological, and antimicrobial analysis were carried out to analyze the newly developed composite insole. Regarding physical testing, different analyses were conducted including tensile strength (SATRA TM137), flexing endurance (SATRA STM 465), water absorption (ASTM D570), and hardness (ASTM D2240) test. Investigation of chemical bonding was performed via Fourier transform infrared (FTIR) spectroscopy (between 4000 and $500 \mathrm{~cm}^{-1}$ spectral range with a resolution of $4 \mathrm{~cm}^{-1}$ ). The surface morphology of the composites was studied by scanning electron microscopy (SEM) JSM-6701F (JEOL, Japan). The availability and structural analysis of buffing dust/ZnONP composites were conducted by powder X-ray diffraction D/Max $2500 \mathrm{~V} / \mathrm{PC}$ (Rigaku Corporation, Tokyo, Japan) $(\mathrm{Cu} \mathrm{K} \alpha \sim 0.1541 \mathrm{~nm})$ at a scan rate of $2^{\circ}(2 \theta) \mathrm{min}^{-1}$. Thermogravimetric analysis (TGA) and oxygen transmission rate (OTR) were experimented by TGA 2950 thermogravimetric analyzer and ASTM D3985, respectively.

2.5. Antimicrobial Properties. Antimicrobial activity of different composite samples coated with ZnONPs was evaluated by the following of immersion and capacity test method. For this purpose, four different suspensions of different concentrations $\left(1.5 \times 10^{6}, 1.5 \times 10^{7}, 1.5 \times 10^{8}\right.$, and $3 \times 10^{8} \mathrm{CFU} / \mathrm{mL}$ ) were also exposed to the nanoparticlecoated composite with different rations. To conduct this, each piece of composite sheet $\left(1 \times 1 \mathrm{~cm}^{2}\right)$ was initially sterilized with ethanol (70\% purity) for 15 minutes. Then, the five different composite samples were placed in different tubes with $1 \mathrm{~mL}$ of bacterial suspension. After 24 hours of incubation, $10 \mu \mathrm{l}$ of the suspension was poured into five different plates with Mueller Hinton Agar media and incubated again for the next 24 hours. Finally, the colony counter was used to enumerate the formed colonies and compared between composite samples as well as controlled suspensions [30].

\section{Results and Discussion}

3.1. FT-IR Spectroscopy Analysis. FTIR spectra of pure buffing dust and composite (sample 3) are represented in Figure 1. In the case of pure buffing dust, a broad peak in the range of $\sim 3400 \mathrm{~cm}^{-1}$ was ascribed to the hydroxyl group (possible from $\mathrm{COOH}$ and $\mathrm{H}_{2} \mathrm{O}$ ). The peak at $\sim 2950 \mathrm{~cm}^{-1}$ indicates the presence of $\mathrm{C}-\mathrm{H}$ groups from protein chain of the materials [31]. Moreover, the typical peaks at $\sim 1640$, $\sim 1420$, and $1120 \mathrm{~cm}^{-1}$ were corresponding to the stretching vibration of $\mathrm{C}-\mathrm{O}, \mathrm{N}-\mathrm{H}$, and $\mathrm{C}=\mathrm{C}$ due to protein molecules and amino acids, respectively [32]. However, it is notewor- thy that the characteristic peaks appeared with significantly higher intensities in FTIR spectra of composite. It is interesting to inform that few new peaks are appeared with lower intensities at the range of $\sim 1100$ to $1300 \mathrm{~cm}^{-1}$ due to hybridized $\mathrm{C}=\mathrm{C}$ (in-plane stretching) of buffing dust and ZnONPs. In addition, a new peak with higher intensity also attributed at $\sim 1000 \mathrm{~cm}^{-1}$ due to the presence of disubstituted alkenes [33]. All of the aforementioned observations confirmed strong chemical interaction between buffing dust and ZnONPs with the help of NRL.

3.2. XRD Analysis. To investigate the structure of composite, XRD analysis of pure buffing dust, ZnONPs and ZnONPs/ buffing dust composites were carried out and are presented in Figure 2. It is clear from the figure that the pure buffing dust shows only two diffraction peaks of at $20^{\circ}$ to $45^{\circ}$ which are associated with collagen structure. This is similar to the image of the collagen fibers. The wide diffraction peak of 2 $\theta=26^{\circ}$ mainly reflects the distance between the molecular chains of the collagen fibers and belongs to the $\alpha$-helix region with more ordered structure. Also, there is a significantly small peak at $2 \theta=43^{\circ}$, due to the numerous structural layers inside the collagen fibers, such as the $\beta$-fold with irregular structure [34]. The XRD patterns of ZnONPs and ZnONPs/buffing dust composite exhibit four diffraction peaks which may be indexed to the (311), (400), (511), and (440) planes of different structures of ZnONPs. In addition, a broad diffraction peak centered at $2 \theta=26^{\circ}$ is also detected, which merely showed elongation of chain cross links and amorphous interaction with collagen [35]. These observations suggest that $\mathrm{ZnONPs}$ were successfully grown on the surface of the buffing dust sheets resulting in the formation of the ZnONPs/buffing dust composite.

3.3. Oxygen Gas Barrier Properties. Figure 3 shows the oxygen gas transmittance rates (OTR) of pure buffing dust as well as composites film at room temperature. Basically, in dry and humid conditions, fiber-based composite film is posses with poor moisture and oxygen barrier capacity. However, the addition of ZnONPs slightly improves the oxygen barrier performance of resulting polymer composites compared to pure one. In general, the higher the surface charge density is of composites, the better the barrier performance of coated polymers [36]. Like other oxygen barriers such as ethylene vinyl alcohol and cellophane, the moisture sensitivity and seal-ability of nanoparticles can be improved by sandwiching them with high moisture-resistant polymers such as a polyolefin [37]. In this study, the OTR value of pure buffing dust film was $160 \pm 3.50 \mathrm{cc} / \mathrm{m}^{2}$.d.atm while composite film OTR value was slightly higher $175 \pm 3.70 \mathrm{cc}$ $/ \mathrm{m}^{2}$.d.atm. Here, trivial increase is observed in oxygen barrier properties due to the coating of ZnONPs in composite film. It was also observed that a lower surface energy of the ZnONP film resulted in higher oxygen permeability, indicating the effect of the interactions between ZnONPs and substrates. These results demonstrated that $\mathrm{ZnONPs}$ are therefore also considered to be a promising multifunctional coating for leather insole. 


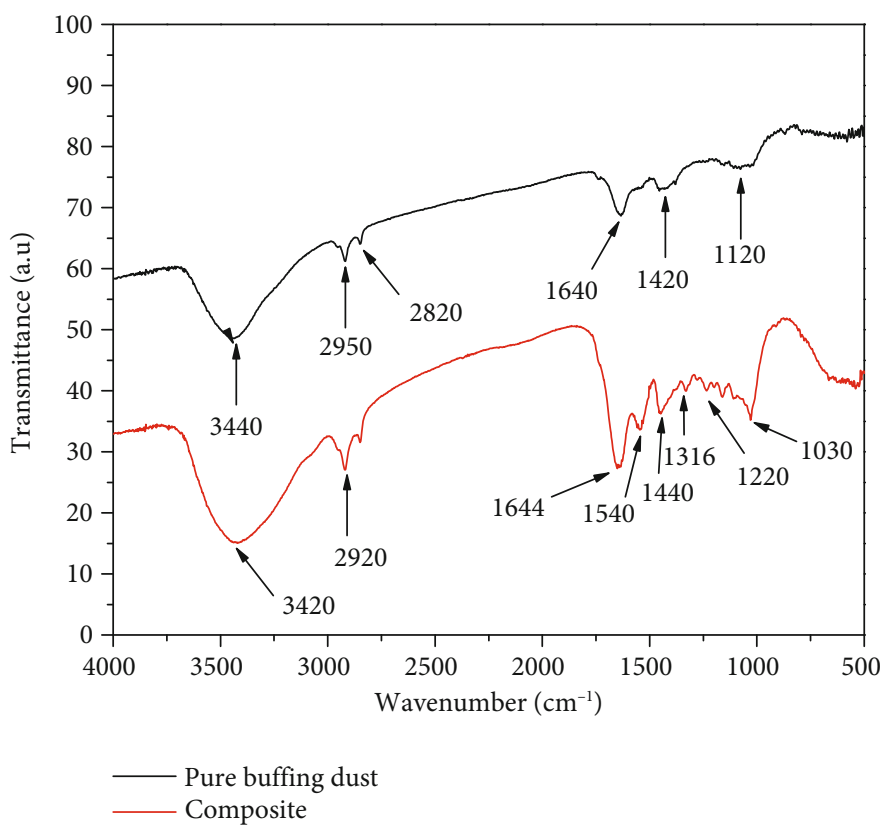

FIGURE 1: FTIR spectroscopy of pure buffing dust and composite.

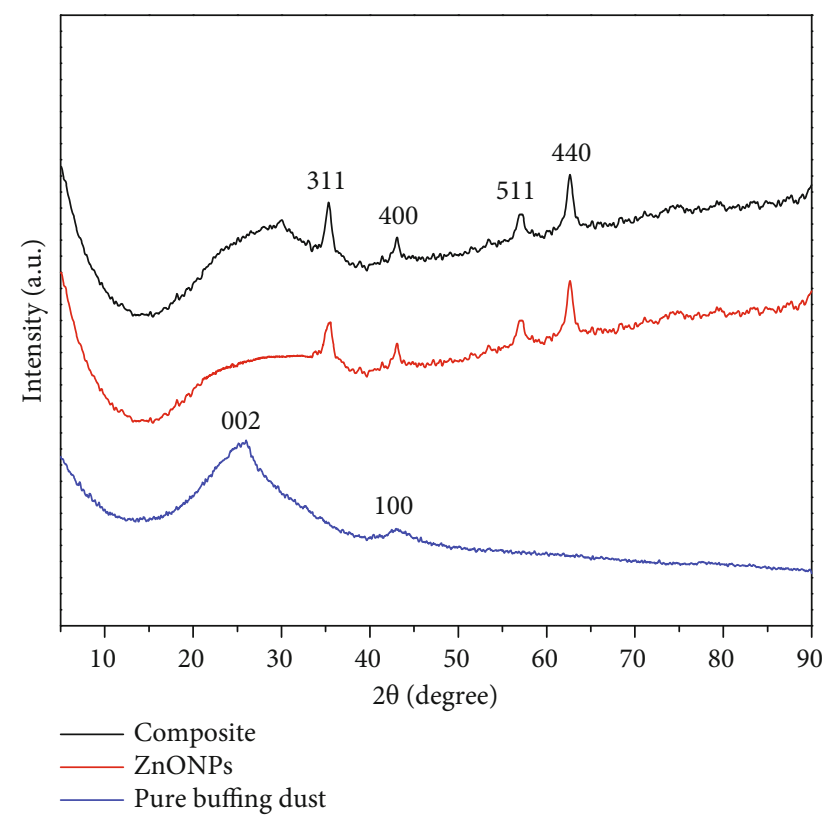

FIgURE 2: XRD analysis of pure buffing dust and composite.

3.4. TGA Analysis. Thermal stability of pure buffing dust and composites film is presented in Figure 4. From the figure, it is clear that weight loss of both materials happened within three steps. At first, 5\% weight of pure buffing dust was decreased with uprising temperature at $100^{\circ} \mathrm{C}$ due to the evaporation of moisture [38]. Then, further degradation was noticed because of organic compounds decomposition including protein, fat, synthetic tannin of buffing dust up to $25 \%$ at around $200-500^{\circ} \mathrm{C}$, and component exhaustion were continued up to $800^{\circ} \mathrm{C}$ [39]. On the other hand, composite sheet with optimum NRL content was degraded slowly and more statically than pure buffing dust. Although degradation pattern was also circumscribed within three steps like previous component. In this case, the utilization of NRL was responsible for strong chemical bonding between interfacial fibers of composite, and higher decomposition temperature of binder $\left(200-500^{\circ} \mathrm{C}\right)$ played a vital role to make the composite more stable against increased temperature. Hence, $18 \%$ decomposition was noticed at around $500^{\circ} \mathrm{C}$. While the material was completely exhausted at $800^{\circ} \mathrm{C}[40,41]$. So, this analysis is indicating higher thermal stability of composite than pure buffing dust.

3.5. SEM Analysis. The surface morphology of synthesized products was further analyzed using SEM and shown in Figure 5. It is clear to analyze that pure buffing dust film shows the fiber-like structure which is produced during liquid evaporation. The morphology of the composites is densely packed with uniform distribution throughout the buffing dust matrix in the composites film. From this reflection, we considered that a strong interfacial interaction occurs between buffing dust and ZnONPs with help of NRL.

3.6. Tensile Strength Test. Tensile strength of different composite samples is represented in Table 1. It is clearly evident that S4 showed highest tensile strength (4.65) and percentage of elongation (42\%) both while S1 (3.33, and 32\%, respectively) has lowest. In this case, the mechanical strength of composites solely depends on the percentage of NRL present in fabricated composite. Because NRL binder in composite material is used to enhance the contact between composite fibers which ensure better tensile strength [42]. Specifically, the NRL binder is confirming the uniform networking between the collagens of waste buffing dusts and fortifying the tensile strength of composite [43]. Moreover, tensile strength increases along with the increment of 


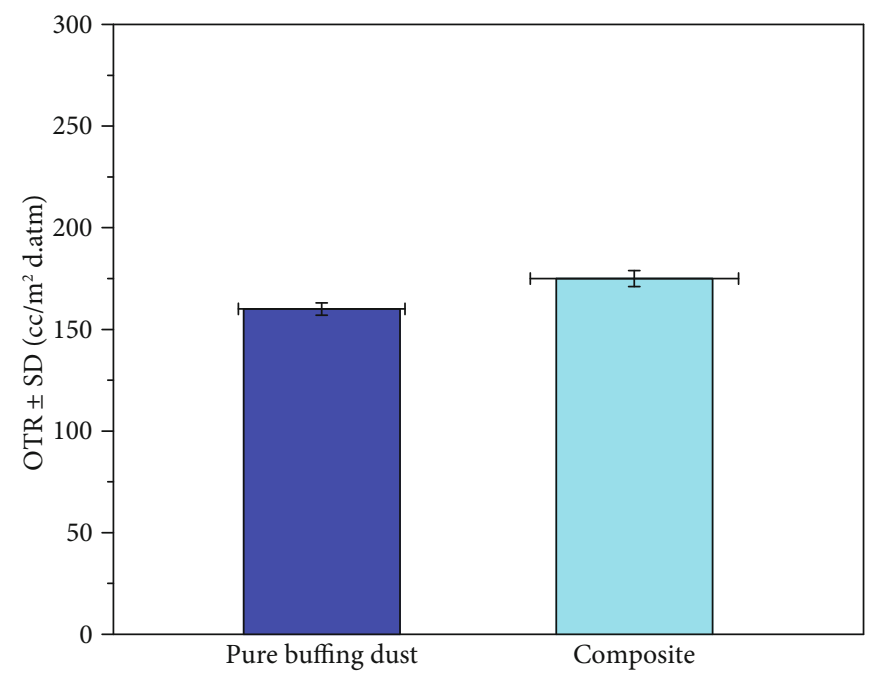

FIgURE 3: Oxygen gas transmittance rates (OTR) of pure buffing dust and composite film.

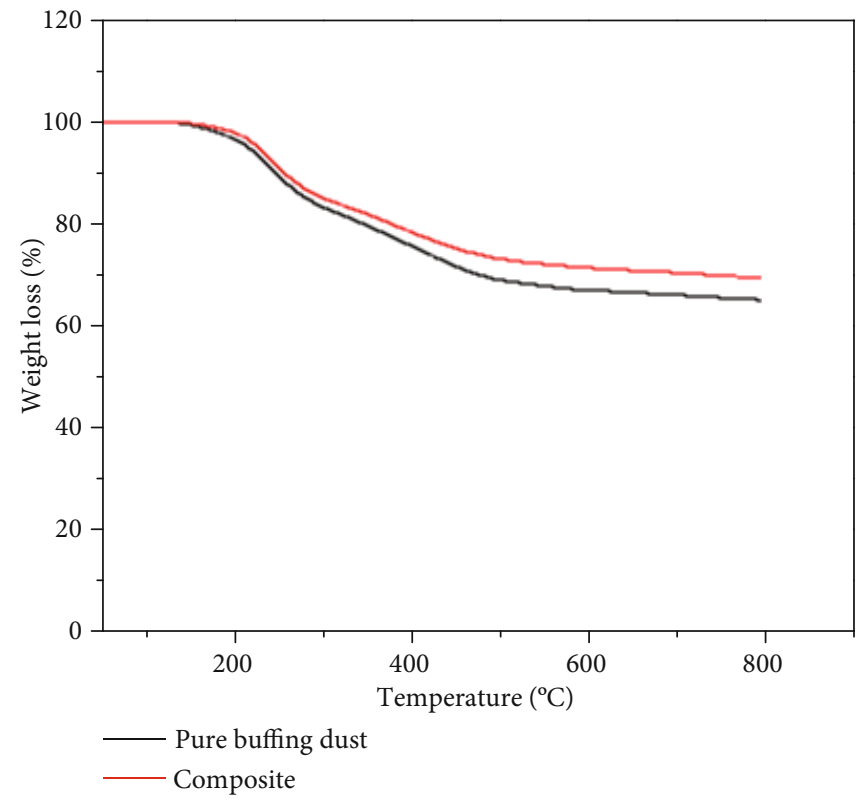

FIGURE 4: TGA of pure buffing dust and composite.

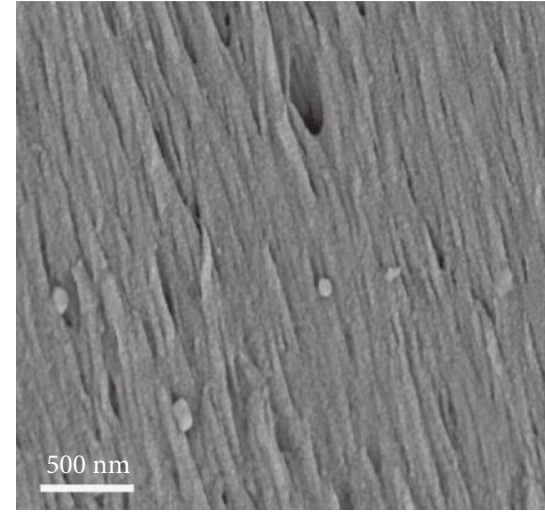

(a)

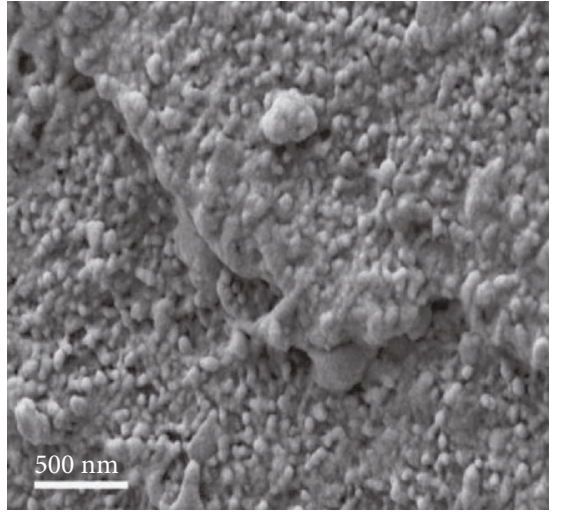

(b)

FIGURE 5: SEM image of pure buffing dust and composite. 
TABLE 1: Mechanical properties of pure buffing dust and various composites.

\begin{tabular}{lccccc}
\hline Sample & Tensile strength $(\mathrm{MPa})$ & Percentage of elongation & Flexing cycles & Water absorption (\%) & Hardness (Pa) \\
\hline S1 & $3.33 \pm 2.85$ & $32.0 \pm 3.10$ & $10000 \pm 5.44$ & $38.09 \pm 2.44$ & $47.66 \pm 3.23$ \\
S2 & $3.78 \pm 3.12$ & $36.0 \pm 2.95$ & $22000 \pm 6.11$ & $36.63 \pm 3.10$ & $62.33 \pm 3.05$ \\
S3 & $4.63 \pm 3.22$ & $41.8 \pm 3.15$ & $40000 \pm 4.20$ & $27.54 \pm 2.44$ & $65.54 \pm 2.42$ \\
S4 & $4.65 \pm 2.70$ & $42.0 \pm 3.17$ & $39150 \pm 4.44$ & $27.94 \pm 2.30$ & $65.5 \pm 3.31$ \\
S5 & $4.62 \pm 2.88$ & $41.12 \pm 2.81$ & $38900 \pm 3.22$ & $27.63 \pm 3.12$ & $64.91 \pm 3.10$ \\
\hline
\end{tabular}

percentage of elongation due to the higher percentage of collagen content in buffing dust with uniform fiber networking [44]. In consequence, strength and elongation both were gradually enhancing with the increase of NRL amount. But in the case of S3, the performance of NRL binder was in equilibrium and result in the slow increase of mechanical performance in S4 and S5. As a result, S3 was considered as optimum to minimize material consumption.

3.7. Flexing Endurance Test. Here, Table 1 provided the flexing endurance of five different composites. It was found that S1 has lowest flexing resistance while S3 has the highest. This may be attributed due to the gradual increase of NRL concentration in fabricated composite. NRL has a tendency to increase ductility as well as flexibility of the composite through the uniform and deeper penetration into the fibers [45], and such phenomena is also noticed by Ahmad et al. [46] during the experimentation with NRL. As a result, flexing endurance was gradually increased due to the successive introduction of NRL binder. Here, both S4 and S5 were also provided significant endurance but slightly lower than S3. So, among them, S3 was considered as optimum sample due to the similar performance than remaining despite of further NRL addition with S4 and S5, respectively.

3.8. Water Absorption Test. This test was carried out for eight hours duration to emulate the practical scenario of footwear use to absorb sweat. Because, such property has direct impact on organic composite stability and odors forming tendency via microbial activity. Here, Table 1 is representing the water absorption properties of five different composite samples. It is clearly evident that S3 showed lowest water absorbance properties with the increase of NRL amount compared to other samples. This may happen due to the minimization of connected porosity with the increase of NRL binder. Moreover, binder in composite preparation is used for exposing this reinforcing material to cover composite aggregate completely. As a result, such application reduces the composite porosity which ultimately mitigates water absorption property and increases aggregate size simultaneously $[47,48]$.

3.9. Hardness Test. This test defined the resistance of the material against a fixed force (load). Here, Table 1 is demonstrating the hardness of five different composite samples. It was observed that S3, S4, and S5 had almost similar hardness property. But, S3 was considered as optimum because gradual addition of binder cannot address additional hardness and indicates the saturation regarding composite performance. This phenomenon may indicate the proportional relationship between tensile strength and hardness of composite which was clearly highlighted during the experimentation $[49,50]$.

3.10. Antimicrobial Activity Test. Antimicrobial test is defined the inhibition of bacterial growth in composite material through the counting of bacterial colonies after antimicrobial treatment. Such property is mandatory for the insole as well as upper lining materials during the footwear use to encounter unpleasant odors. Here, Table 2 is representing the antimicrobial performance of different composites coated with different concentrations of ZnONPs. It is clearly evident that the antimicrobial activity is increasing with the increase of $\mathrm{ZnONP}$ concentrations into composite materials. This can be attributed by the fact that after coating with the increased concentration of $\mathrm{ZnO}$ based aqueous suspension, two probable mechanisms are playing the antimicrobial role including (i) formation of reactive oxygen radicals that impart antimicrobial activity via oxidative stress, (ii) rupturing of bacterial cell membrane by introduced nanoparticles as well as deposition of such particles into the cytoplasm which are also resulting the bacterial dead. As a result, with the gradual increment of nanoparticles ratio, the bacterial concentrations are rapidly diminishing up to the S3. While in case of S4 and S5, almost similar antibacterial efficiency is noticed like S3. This may happen due to the presence of optimum amount of nanoparticles present in S3 to inhibit the maximum percentage of bacterial growth in composite surface. Another fact is also prominent to notice that the antibacterial performance of ZnONPs was sharply decreasing in terms of the highly concentrated suspension like $3 \times 10^{8} \mathrm{CFU} / \mathrm{mL}$. Although, the bacterial growth in composite samples was even lower than controlled microbial suspension for this concentration. However, it can be claimed that these fabricated composites can inhibit bacterial growth up to the concentration of suspension $1.5 \times 10^{8} \mathrm{CFU} / \mathrm{mL}$, and highest antimicrobial efficiency $(78 \%)$ was obtained against the bacterial concentration of $1.5 \times 10^{6} \mathrm{CFU} / \mathrm{mL}$ for sample 3 (S3). More elaborately in sample 3 , the microbial concentration was sharply reduced to $1015 \pm 3.45 \mathrm{CFU} / \mathrm{mL}$ while the initial concentration of suspension was $4500 \pm 3.10 \mathrm{CFU} / \mathrm{mL}$.

Here, Table 3 is representing the comparison between the experimental studies on antimicrobial activity against the strain of Staphylococcus aureus. In order to construct antimicrobial footwear, the investigations regarding finished 
TABLE 2: Antimicrobial activity of various composite samples.

\begin{tabular}{lcccc}
\hline Sample different concentrations of S. aureus & & & \\
& $1.5 \times 10^{6} \mathrm{CFU} / \mathrm{mL}$ & $1.5 \times 10^{7} \mathrm{CFU} / \mathrm{mL}$ & $1.5 \times 10^{8} \mathrm{CFU} / \mathrm{mL}$ & $3 \times 10^{8} \mathrm{CFU} / \mathrm{mL}$ \\
\hline Suspension & $4500 \pm 3.10$ & $6500 \pm 3.89$ & $7900 \pm 3.88$ & $9500 \pm 2.92$ \\
S1 & $2200 \pm 3.70$ & $3700 \pm 3.45$ & $7200 \pm 2.86$ & $9200 \pm 2.95$ \\
S2 & $1650 \pm 2.85$ & $2100 \pm 3.22$ & $6640 \pm 2.97$ & $8900 \pm 3.85$ \\
S3 & $1015 \pm 3.45$ & $1965 \pm 3.10$ & $5930 \pm 3.82$ & $8835 \pm 3.75$ \\
S4 & $995 \pm 3.05$ & $1810 \pm 2.94$ & $5810 \pm 3.88$ & $8785 \pm 2.87$ \\
S5 & $989 \pm 2.98$ & & $5765 \pm 3.92$ & $8715 \pm 3.89$ \\
\hline
\end{tabular}

TABLE 3: Comparison of antibacterial performance of various studies.

\begin{tabular}{lccccc}
\hline Material & Antimicrobial assay & Bacterial strains & NPs & Inhibition efficiency & Ref. \\
\hline Buffing dust composite & Immersion method & Staphylococcus aureus & ZnONPs & 78.0 & This study \\
Finished leather & Immersion method & Staphylococcus aureus & AgNPs & 99.0 & {$[12]$} \\
Lining leather & Agar overlay method & Staphylococcus aureus & Ag-TiO $_{2} \mathrm{NPs}$ & 99.0 & {$[16]$} \\
Finished leather & Agar diffusion method & Staphylococcus aureus & AgNPs & - & {$[14]$} \\
Tanned leather & Disk diffusion method & Staphylococcus epidermidis & AgNPs & 46.6 & {$[51]$} \\
Cotton fabrics & Immersion method & Staphylococcus aureus & AgNPs & 99.0 & {$[52]$} \\
Cotton fabrics & Standard AATCC 100 & Staphylococcus aureus & AuNPs & 63.9 & {$[53]$} \\
Cotton fabrics & Disk diffusion method & Staphylococcus aureus & AgNPs & 89.0 & {$[54]$} \\
Non-woven fabrics & Disk diffusion method & Staphylococcus aureus & AgNPs & 72.9 & {$[55]$} \\
\hline
\end{tabular}

leather, tanned leather, and cotton fabrics are mostly prominent. But to ensure antimicrobial property in footwear, the insole material is most important to consider due to its direct contact with foot bottom. Thus, the fabrication of antimicrobial insole is inevitable to encounter bad odor as well as the growth of pathogenic bacteria during the footwear use. This crucial phenomenon is considered in this study to justify the novelty which was absent in previous experimentations. Regarding applied nanoparticles as antimicrobial agent, AgNPs are mostly used against microbes and imparting $99 \%$ inhibition efficiency. But problems are associated with such nanoparticles due to their commercial production as well as industrial applications. Specifically, rapid utilization of AgNPs is causing frequent discharge into the environment and is responsible for secondary pollution. The most acute problems are including malfunctioning of the nitrogen cycle, disrupting aquatic ecosystems, inhibition of material decomposition, reduction of plant biomass, degradation of microbial biomass, and altering physiological process due to the bioaccumulation of Ag nanoparticles into plant tissues [56]. After considering all of these points, the study was aimed to use ZnONPs during the fabrication of antibacterial composites with waste buffing dust. Although the overall bactericidal efficacy was only $78 \%$, while such output is compensating with environmental safety rather than using silver-based nanoparticles which result in another environmental hazards as well. Moreover, the fabricated composites are also prospective regarding mechanical, thermal, and oxygen gas barrier properties and are highly competitive to use commercially as shoe insole material.
This composite is also potential to be utilized in decorative and packaging purpose as well.

\section{Conclusions}

In summary, this study is to fabricate an antimicrobial composite insole material along with associated mechanical properties including flexibility, higher tensile strength, hardness, and water absorption capacity. Moreover, assurance of sufficient thermal stability and compatible chemical properties is also integral consideration during the study. However, after completing fabrication followed by performance analysis, the major findings ensured the rationality of assembled composite as antimicrobial footwear insole with simultaneous environmental safety. More elaborately, a simple solution casting method was used to create zinc oxide nanoparticle reinforced waste buffing dust with NRL composites. FTIR, XRD, TGA, SEM, and OTR characterization were used to examine chemical bonding, material structure, thermal strength, surface morphology, and gas barrier properties, respectively. Finally, highest mechanical, thermal, antimicrobial, and oxygen gas barrier properties have been found for the sample 3 (S3) with ratio of waste buffing dust: water: NRL: ZnONPs $1: 2: 2.3: 0.2$, respectively. However, these simple, cost effective, and flexible composite materials would be extremely promising for the production of footwear insole commercially. In addition, this composite can also be used as packing and decorative purpose where flexibility is the major concern. 


\section{Data Availability}

No data were used to support the findings of this study.

\section{Additional Points}

Highlights. (1) ZnONPs can provide 78\% antimicrobial activity against Staphylococcus aureus. (2) The optimum concentration of NRL is vital for composite strength and flexibility. (3) Static networking between collagen fibers and nanoparticles is crucial to consider. (4) Environmental pollution load can be reduced by the utilization of waste materials.

\section{Consent}

Consent is not applicable.

\section{Conflicts of Interest}

The authors do not have any competing interests.

\section{Authors' Contributions}

TKD conducted experimentation in laboratory. $\mathrm{AH}$ analyzed and interpreted the experimental data. RKL, TKD, and $\mathrm{AH}$ characterized the sample. MJ reviewed the manuscript. MEU performed the idea generation, evaluation, and interpreted of overall experimentation. All authors participated in writing the manuscript read and approved the final manuscript.

\section{Acknowledgments}

This study was supported by Research and Extension (R\&E), Khulna University of Engineering \& Technology, Khulna, Bangladesh (2019-2020). Rama K. Layek acknowledges the Academy of Finland's postdoctoral funding no. 345006.

\section{References}

[1] L. B. Baker, "Physiology of sweat gland function: the roles of sweating and sweat composition in human health," Temperature, vol. 6, no. 3, pp. 211-259, 2019.

[2] G. Gran, "Investigations on shoe climate and foot comfort," Society of Leather Technologists and Chemists, vol. 43, pp. 182-197, 1957.

[3] E. Irzmańska, J. K. Dutkiewicz, and R. Irzmański, "New approach to assessing comfort of use of protective footwear with a textile liner and its impact on foot physiology," Textile Research Journal, vol. 84, no. 7, pp. 728-738, 2014.

[4] C. J. Smith, C. A. Machado-Moreira, G. Plant, S. Hodder, G. Havenith, and N. A. S. Taylor, "Design data for footwear: sweating distribution on the human foot," International Journal of Clothing Science and Technology, vol. 25, no. 1, pp. 43-58, 2013.

[5] E. Arens and H. Zhang, "The skin's role in human thermoregulation and comfort," in Thermal and Moisture Transport in Fibrous Materials, N. Pan and P. Gibson, Eds., pp. 560-602, Woodhead Publishing Ltd, 2006.

[6] Y. Urabe, N. Maeda, S. Kato, H. Shinohara, and J. Sasadai, "Effect of shoe insole for prevention and treatment of lower extremity injuries," The Journal of Physical Fitness and Sports Medicine, vol. 3, no. 4, pp. 385-398, 2014.

[7] E. Irzmańska and A. Brochocka, "Influence of the physical and chemical properties of composite insoles on the microclimate in protective footwear," Fibrese Textiles in Eastern Europe, vol. 5, no. 107, pp. 89-95, 2014.

[8] J. H. Thornton, “A Glossary of Shoe Terms," Costume, vol. 11, no. 1, pp. 28-33, 1977.

[9] F. Crawford, R. Hart, S. E. M. Bell-Syer, D. J. Torgerson, P. Young, and I. Russell, "Extracts from "Clinical Evidence": Athlete's foot and fungally infected toenails," BMJ, vol. 322, no. 7281, pp. 288-289, 2001.

[10] H. Gu, C. Zhao, L. Wang, Y. Gong, and W. Chen, A New Combined Antimicrobial Agent: Development and Application in Shoe Lining Leather, Congress IULTCS, Beijing, China, 2009.

[11] A. J. Boulton, L. Vileikyte, G. Ragnarson-Tennvall, and J. Apelqvist, "The global burden of diabetic foot disease," The Lancet, vol. 366, no. 9498, pp. 1719-1724, 2005.

[12] Z. Majidnia, A. Idris, and P. Valipour, "Evaluation of antibacterial properties of leather treated with silver nanoparticles," Jurnal Teknologi, vol. 60, no. 1, pp. 5-8, 2012.

[13] A. Idris, Z. Majidnia, P. Valipour, and I. Ghaemshahr, "Antibacterial improvement of leather by surface modification using corona discharge and silver nanoparticles application," Journal of Science and Technology, vol. 5, no. 2, pp. 1-15, 2013.

[14] I. M. Maestre-López, F. J. Payà-Nohales, N. Cuesta-Garrote et al., "Antimicrobial effect of coated leather based on silver nanoparticles and nanocomposites: synthesis, characterisation and microbiological evaluation," Journal of Biotechnology \& Biomaterials, vol. 5, no. 1, p. 1, 2015.

[15] I. Carvalho, S. Ferdov, C. Mansilla et al., "Development of antimicrobial leather modified with $\mathrm{Ag}-\mathrm{TiO}_{2}$ nanoparticles for footwear industry," Science and Technology of Materials, vol. 30, pp. 60-68, 2018.

[16] M. K. Kaygusuz, N. Lkhagvajav, I. Yaşa, and E. Celik, "Antimicrobial nano-Ag- $\mathrm{TiO}_{2}$ coating for lining leather," Romanian Biotechnological Letters, vol. 21, no. 5, p. 11866, 2016.

[17] J. Kwiczak-Yiğitbaşı, Ö. Laçin, M. Demir, R. E. Ahan, U. Ö. Ş. Şeker, and B. Baytekin, "A sustainable preparation of catalytically active and antibacterial cellulose metal nanocompositesviaball milling of cellulose," Green Chemistry, vol. 22, no. 2, pp. 455-464, 2020.

[18] N. Liu, X. Li, J. Li, Y. Cao, and L. Feng, "Hierarchical architectures of Ag clusters deposited biomimetic membrane: synthesis, emulsion separation, catalytic and antibacterial performance," Separation and Purification Technology, vol. 241, article 116733, 2020.

[19] V. Voros, E. Drioli, C. Fonte, and G. Szekely, "Process intensification via continuous and simultaneous isolation of antioxidants: an upcycling approach for olive leaf waste," ACS Sustainable Chemistry \& Engineering, vol. 7, no. 22, pp. 18444-18452, 2019.

[20] H. R. Nawaz, B. A. Solangi, B. Zehra, and U. Nadeem, "Preparation of nano zinc oxide and its application in leather as a retanning and antibacterial agent," Canadian Journal on Scientific and Industrial Research, vol. 2, no. 4, pp. 164-170, 2011.

[21] C. Gaidau, M. A. D. A. L. I. N. A. Ignat, O. V. I. D. I. U. Iordache et al., " $\mathrm{ZnO}$ nanoparticles for antimicrobial treatment of leather surface," Revista de Chimie, vol. 69, no. 4, pp. 767-771, 2018.

[22] C. S. Chakra, V. Rajendar, K. V. Rao, and M. Kumar, "Enhanced antimicrobial and anticancer properties of $\mathrm{ZnO}$ 
and TiO2 nanocomposites," Biotech, vol. 7, no. 2, pp. 1-8, 2017.

[23] A. Sirelkhatim, S. Mahmud, A. Seeni et al., "Review on zinc oxide nanoparticles: antibacterial activity and toxicity mechanism," Nano-Micro Letters, vol. 7, no. 3, pp. 219-242, 2015.

[24] R. Perveen, S. Shujaat, Z. Qureshi, S. Nawaz, M. I. Khan, and M. Iqbal, "Green versus sol-gel synthesis of $\mathrm{ZnO}$ nanoparticles and antimicrobial activity evaluation against panel of pathogens," Journal of Materials Research and Technology, vol. 9, no. 4, pp. 7817-7827, 2020.

[25] J. Pasquet, Y. Chevalier, J. Pelletier, E. Couval, D. Bouvier, and M. A. Bolzinger, "The contribution of zinc ions to the antimicrobial activity of zinc oxide," Colloids and Surfaces A: Physicochemical and Engineering Aspects, vol. 457, pp. 263-274, 2014.

[26] K. S. Siddiqi, A. ur Rahman, Tajuddin, and A. Husen, "Properties of zinc oxide nanoparticles and their activity against microbes," Nanoscale Research Letters, vol. 13, no. 1, pp. 1-13, 2018.

[27] J. Kanagaraj, K. C. Velappan, N. K. Babu, and S. Sadulla, "Solid wastes generation in the leather industry and its utilization for cleaner Environment," ChemInform, vol. 37, no. 49, pp. 541548, 2006.

[28] R. Senthil, T. Hemalatha, R. Manikandan, B. N. Das, and T. P. Sastry, "Leather boards from buffing dust: a novel perspective," Clean Technologies and Environmental Policy, vol. 17, no. 2, pp. 571-576, 2015.

[29] A. Livingston, B. L. Trout, I. T. Horvath, M. D. Johnson, L. Vaccaro, J. Coronas, and C. W. Babbitt, Eds., "Challenges and Directions for Green Chemical Engineering-Role of Nanoscale Materials," Sustainable Nanoscale Engineering, pp. 1-18, 2020.

[30] Technical Committee ISO/TC 61, Plastics, Subcommittee SC 6, Ageing, Chemical and Environmental Resistance, International Standard ISO 22196, 1st edition, 2007.

[31] H. Ozgunay, S. E. L. İ. M. E. Çolak, M. M. Mutlu, and F. Akyuz, "Characterization of leather industry wastes," Polish Journal of Environmental Studies, vol. 16, no. 6, pp. 867-873, 2007.

[32] S. Swarnalatha, T. Srinivasulu, M. Srimurali, and G. Sekaran, "Safe disposal of toxic chrome buffing dust generated from leather industries," Journal of Hazardous Materials, vol. 150, no. 2, pp. 290-299, 2008.

[33] M. Prochon, A. Marzec, and O. Dzeikala, "Hazardous waste management of buffing dust collagen," Materials, vol. 13, no. 7, p. 1498, 2020.

[34] L. Yu, X. Qiang, L. Cui, B. Chen, X. Wang, and X. Wu, "Preparation of a syntan containing active chlorine groups for chrome-free tanned leather," Journal of Cleaner Production, vol. 270, article 122351, 2020.

[35] M. Srivastava, M. Elias Uddin, J. Singh, N. H. Kim, and J. H. Lee, "Preparation and characterization of self-assembled layer by layer $\mathrm{NiCo}_{2} \mathrm{O}_{4}$-reduced graphene oxide nanocomposite with improved electrocatalytic properties," Journal of Alloys and Compounds, vol. 590, pp. 266-276, 2014.

[36] C. S. Gil, V. S. Gil, S. M. Carvalho et al., "Recycled collagen films as biomaterials for controlled drug delivery," New Journal of Chemistry, vol. 40, no. 10, pp. 8502-8510, 2016.

[37] M. A. S. P. Nur Hazirah, M. I. N. Isa, and N. M. Sarbon, "Effect of xanthan gum on the physical and mechanical properties of gelatin- carboxymethyl cellulose film blends," Food Packaging and Shelf Life, vol. 9, pp. 55-63, 2016.
[38] Z. N. Azwa, B. F. Yousif, A. C. Manalo, and W. Karunasena, “A review on the degradability of polymeric composites based on natural fibres," Materials \& Design, vol. 47, pp. 424-442, 2013.

[39] S. M. Suresh Kumar, D. A. Duraibabu, and K. Subramanian, "Studies on mechanical, thermal and dynamic mechanical properties of untreated (raw) and treated coconut sheath fiber reinforced epoxy composites," Materials \& Design, vol. 59, pp. 63-69, 2014.

[40] C. He, Y. Wang, Y. Luo, L. Kong, and Z. Peng, "Thermal degradation kinetics and mechanism of epoxidized natural rubber," Journal of Polymer Engineering, vol. 33, no. 4, pp. 331335, 2013.

[41] S. N. Monteiro, V. Calado, R. J. S. Rodriguez, and F. M. Margem, "Thermogravimetric behavior of natural fibers reinforced polymer composites-An overview," Materials Science and Engineering: A, vol. 557, pp. 17-28, 2012.

[42] M. Amran, R. Izamshah, M. Hadzley et al., "The effect of binder on mechanical properties of kenaffibre/polypropylene composites using full factorial method," Applied Mechanics and Materials, vol. 695, pp. 709-712, 2014.

[43] A. Islam, Y. Molla, T. K. Dey, M. Jamal, R. Rathanasamy, and M. Uddin, "Latex reinforced waste buffing dust-jeans cotton composites and its characterization," Journal of Polymer Research, vol. 28, no. 8, pp. 1-8, 2021.

[44] P. Saikia, T. Goswami, D. Dutta, N. K. Dutta, P. Sengupta, and D. Neog, "Development of a flexible composite from leather industry waste and evaluation of their physico-chemical properties," Clean Technologies and Environmental Policy, vol. 19, no. 8, pp. 2171-2178, 2017.

[45] M. Fredriksson and S. Forsberg, "Wood fibre composites with high fibre content," Fiber Science and Communication Network, 2005.

[46] M. R. Ahmad, W. Y. W. Ahmad, A. Samsuri, and J. Salleh, "Ballistic response of natural rubber latex coated and uncoated fabric systems," Journal of Rubber Research, vol. 10, no. 4, pp. 207-221, 2007.

[47] T. C. Fu, W. Yeih, J. J. Chang, and R. Huang, "The influence of aggregate size and binder material on the properties of pervious concrete," Advances in Materials Science and Engineering, vol. 2014, Article ID 963971, 17 pages, 2014.

[48] M. Brebu, "Environmental degradation of plastic composites with natural fillers-a review," Polymers, vol. 12, no. 1, p. 166, 2020.

[49] M. Gaško and G. Rosenberg, "Correlation between hardness and tensile properties in ultra-high strength dual phase steels-short communication," Journal of Material Engineering, vol. 18, no. 4, pp. 155-159, 2011.

[50] P. Zhang, S. X. Li, and Z. F. Zhang, "General relationship between strength and hardness," Materials Science and Engineering: A, vol. 529, pp. 62-73, 2011.

[51] P. Velmurugan, M. Cho, S. M. Lee, J. H. Park, S. Bae, and B. T. Oh, "Antimicrobial fabrication of cotton fabric and leather using green-synthesized nanosilver," Carbohydrate Polymers, vol. 106, pp. 319-325, 2014.

[52] T. C. Prathna, M. Raichur, N. Chandrasekaran, and A. Mukherjee, "Process development for functionalization of cotton with silver nanoparticles synthesized by bio-based approaches," Current Nanoscience, vol. 9, no. 4, pp. 479-488, 2013.

[53] R. M. Ganesan and H. Gurumallesh Prabu, "Synthesis of gold nanoparticles using herbal_Acorus calamus_rhizome extract 
and coating on cotton fabric for antibacterial and UV blocking applications," Arabian Journal of Chemistry, vol. 12, no. 8, pp. 2166-2174, 2019.

[54] P. Sharma, S. Pant, S. Rai, R. B. Yadav, S. Sharma, and V. Dave, "Green synthesis and characterization of silver nanoparticles by Allium cepa L. to produce silver nano-coated fabric and their antimicrobial evaluation," Applied Organometallic Chemistry, vol. 32, no. 3, p. 4146, 2018.

[55] N. Yang and W. H. Li, "Mango peel extract mediated novel route for synthesis of silver nanoparticles and antibacterial application of silver nanoparticles loaded onto non-woven fabrics," Industrial Crops and Products, vol. 48, pp. 81-88, 2013.

[56] B. P. Colman, B. Espinasse, C. J. Richardson et al., "Emerging contaminant or an old toxin in disguise? Silver nanoparticle impacts on ecosystems," Environmental Science \& Technology, vol. 48, no. 9, pp. 5229-5236, 2014. 